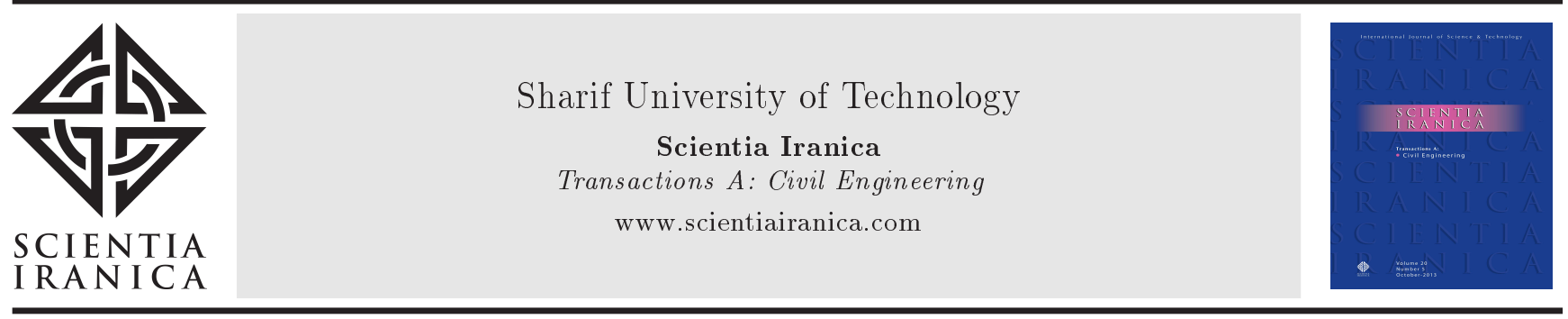

\title{
State of the art on the maximum strength of masonry infilled frames
}

\author{
M. Mohammadi* \\ International Institute of Earthquake Engineering and Seismology (IIEES), No. 21, Arghavan St., Tehran, Iran. \\ Received 6 June 2015; received in revised form 2 February 2016; accepted 7 May 2016
}

KEYWORDS
Strength;
Masonry;
Infill panel;
Seismic design;
Ultimate strength;
Equivalent strut.

\section{Introduction}

Research on structural effects of infill panels was started in 1950 [1]. Infill panels are mostly regarded in mid- and high-rise buildings, despite confined walls which are applied only to short structures. They raise the in-plane stiffness and strength of the structure due to the infill-frame interaction. However, their structural effects are mostly ignored in the structural analysis and design phases, based on many codes' criteria $[2,3]$, which is due to the complexity of modeling and shortcomings in engineering knowledge. This may lead to substantial inaccuracy in predicting the lateral stiffness, strength and ductility of the structure as well as structural element or connection forces, regarding local effects of infills.

*. Corresponding author. Tel.: +982122830830 E-mail address: m.mohammadigh@iiees.ac.ir ( $M$. Mohammadi)
In rehabilitation codes [4-6], infill panels should be considered as primary structural elements. To predict the general behavior of infill and consider infill panel's effects on infilled frame's behavior, Macro-Models are proposed. In such models, an infill panel is modeled as a diagonal member, as shown in Figure 1. The equivalent member, which acts only in compression, has the same thickness and material specifications of the infill panel. The width of section (a) has been studied in many research studies. The expected strength of an infill panel, applied in the rehabilitation codes [4$6]$, is very close to the cracking strength; however, experimental values of the cracking strength are very scattered, and there is not a formula to determine it accurately. That is why some new codes [6] have focused on determining the expected strength by the maximum strength.

The ultimate strength of infilled frames is generally calculated as a function of the equivalent width as follows: 


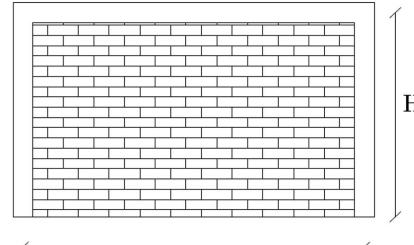

$\mathrm{L}$

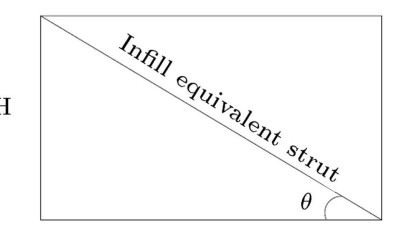

(b) Macro model by equivalent strut
Paulay \& Priestly [8]

Paulay \& Priestly [8] used the same method of Holmes [7]; however, they believed that the width of the infill equivalent diagonal strut is $1 / 4$ of the infill diagonal.

\section{Smith \& Coull [9]}

Smith \& Coull [9] proposed the following relation to calculate the corner crushing strength of masonry infilled frame, which corresponds with the ultimate strength:

$$
F_{u}=f_{m}^{\prime} \times t_{\mathrm{inf}} \times \frac{\pi}{2} \times 4 \sqrt{\frac{4 E_{f} \times I_{f} \times h_{\mathrm{inf}}}{E_{\mathrm{inf}} \times t_{\mathrm{inf}}}},
$$

where $E_{f}$ and $I_{f}$ are moduli of elasticity of frame sections, and $h_{\text {inf }}$ is height of the infill.

\section{Smith [10]}

In 1966, Smith [10] introduced a parameter for the relative stiffness of infill to the frame, shown as $\lambda_{h}$. He related the contact length between the infill and the confining frame to $\lambda_{h}$ and used the finite difference method to analyze infilled frames. $\lambda_{h}$ is as follows:

$$
\lambda_{h}=h_{f} \times 4 \sqrt{\frac{E_{\mathrm{inf}} t_{\mathrm{inf}}}{4 E_{f} I_{f} \times h_{\mathrm{inf}}}} .
$$

In addition, the contact length $(s)$ is calculated as:

$$
s=\frac{\pi}{2 \lambda_{h}} h_{\mathrm{inf}} .
$$

Then, he proposed a graph for the ultimate strength of the infilled frame as a function of $\lambda_{h}$, as shown in Figure 2 .

\section{Mainstone [11,12]}

Mainstone [11,12] applied Eq. (1) for corner crushing strength, assuming that all contact parts of the infill

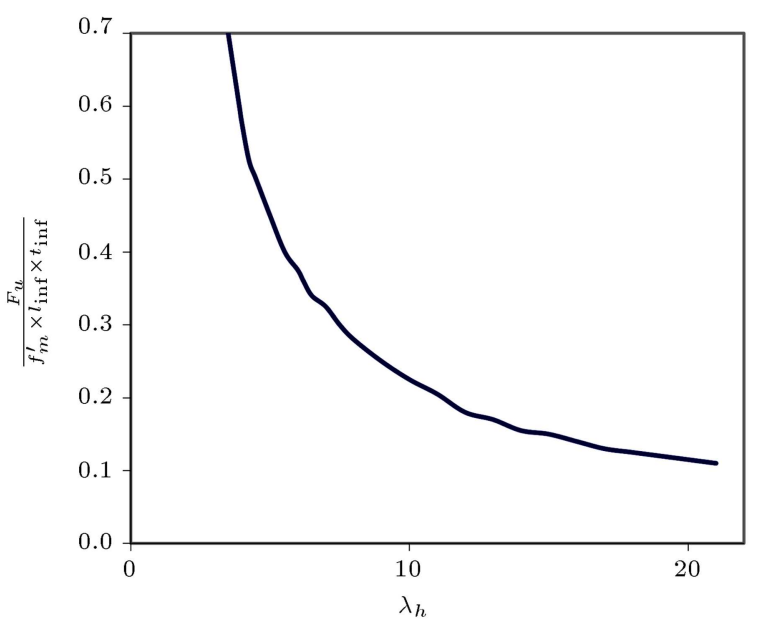

Figure 2. Ultimate strength of infilled frame as a function of $\lambda_{h}$ [10].
Many relations have been already proposed for the ultimate strength of infilled frames. The relations for the ultimate strength of infilled frame are as follows. It is worth mentioning that the relations merely account for the infill equivalent strut width and do not represent the stress distributions which are likely to occur. In other words, applying these relations is proposed just for evaluating the global structural capacity. Local effects, including the stress fields, should be considered by other methods, such as finite elements modeling.

Holms (one third rule) [7]

Holmes [7] suggested to replace the infill by an equivalent pin-jointed diagonal strut made of the same material and having a width $1 / 3$ of the infill diagonal and to calculate the ultimate strength with Eq. (1). 
to the frame elements reach their capacities in the ultimate case. He improved Smith's relation (Eq. (3)) for relative stiffness of infill to the confining frame and proposed the following formula. This relation is applied to FEMA-273, 306, 307, 356 [13-16] and also ASCE-41 [4] to calculate width of infill equivalent strut $(a)$ :

$$
\begin{aligned}
& \lambda_{l}=\left[\frac{E_{\mathrm{inf}} \times t_{\mathrm{inf}} \times \sin (2 \theta)}{4 \times E_{f} \times I_{\mathrm{col}} \times h_{\mathrm{inf}}}\right]^{\frac{1}{4}}, \\
& a=0.175 \times\left(\lambda_{l} \times h_{\mathrm{col}}\right)^{-0.4} r_{\mathrm{inf}},
\end{aligned}
$$

where:

$\lambda_{l} \quad$ Relative stiffness of infill to the frame

$h_{\text {col }} \quad$ Column height up to the centerline of beam

$I_{\text {col }} \quad$ Moment of inertia of column, $\mathrm{m}^{4}$

$r_{\text {inf }} \quad$ Diagonal length of infill panel, $m$

$E_{\text {inf }} \quad$ Modulus of elasticity for infill material (normally assumed as 550 ), $\mathrm{Pa}$

$\theta \quad$ Angle whose tangent is the infill height to length, degrees

Zarnic \& Gostic [17]

Zarnic \& Gostic[17] proposed the following relation for the ultimate strength of infilled frame as a function of cracking strength of infill $\left(f_{t p}\right)$ that is obtained by diagonal compression testing on infill specimens. Dolsec and Fajfar [18] applied these formula to the ultimate strength of infill models and proposed a simple mathematical model for infilled frames, which combines beam elements with concentrated plasticity, simple connection elements, and equivalent strut elements representing the infill walls.

Since measuring $f_{t p}$ is not very common for regular infills and needs a specimen with considerable dimensions, this relation is not used in practice:

$$
F_{u}=0.818 \frac{l_{\mathrm{inf}} \times t_{\mathrm{inf}} \times f_{t p}}{C 1}\left(1+\sqrt{C 1^{2}+1}\right),
$$

where:

$$
C 1=1.925 \frac{l_{\mathrm{inf}}}{h_{\mathrm{inf}}} .
$$

Liauw \& Kwan [20]

Wood [19] was the first to employ the plasticity concept in evaluating the ultimate strength. He assumed four idealized plastic modes of failure, which are as follows: Shear mode (S), Shear Rotation mode (SR), Diagonal Compression mode (DC), and Corner Crushing mode (CC). However, results of Wood's method showed a larger scatter when compared with the experimental results. Therefore, Liauw \& Kwan [20] improved wood's method and considered three failure modes for the infilled frames, shown in Figure 3, which are as follows: a) corner crushing with failure in column; b) corner crushing with failure in beam; and c) diagonal crushing.

They proposed the following relations of the ultimate strength of the infilled frame, based on the assumed failure modes:

$$
\begin{aligned}
F_{u}= & \gamma_{p} \times f_{m}^{\prime} \times t_{\mathrm{inf}} \times h_{\mathrm{inf}} \\
& \times \min \left\{\sqrt{\frac{2\left(M_{p j}+M_{p c}\right)}{\gamma_{p} \times f_{m}^{\prime} \times t_{\mathrm{inf}} \times h_{\mathrm{inf}}^{2}}} \frac{1}{\tan \theta}\right. \\
& \times \sqrt{\frac{2\left(M_{p j}+M_{p b}\right)}{\gamma_{p} \times f_{m}^{\prime} \times t_{\mathrm{inf}} \times h_{\mathrm{inf}}^{2}}} \frac{4 M_{p j}}{\gamma_{p} \times f_{m}^{\prime} \times t_{\mathrm{inf}} \times h_{\mathrm{inf}}^{2}} \\
& \left.+\frac{1}{6 \times \max \left(1, \tan ^{2} \theta\right)}\right\},
\end{aligned}
$$

where $M_{p c}$ and $M_{p b}$ are plastic moments of the column and beam, respectively, and $M_{p j}$ is plastic moment of the joint, the smaller values of $M_{p c}$ or $M_{p b}$. $\gamma_{p}$ is penalty factor, calculated by the following relation, based on comparing the obtained results with experimental values:

$$
\gamma_{p}=2.663 \mathrm{~m}^{3}-1.37 \mathrm{~m}+0.406 \leq 0.45,
$$

and:

$$
m=\frac{8 M_{p j}}{f_{m}^{\prime} \times t_{\mathrm{inf}} \times l_{\mathrm{inf}}^{2}} .
$$

\section{Saneinejad and Hobbs [21]}

Saneinejad and Hobbs [21] suggested the following relation for the ultimate strength of the infilled frame,

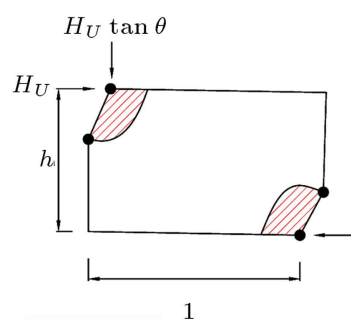

(a)

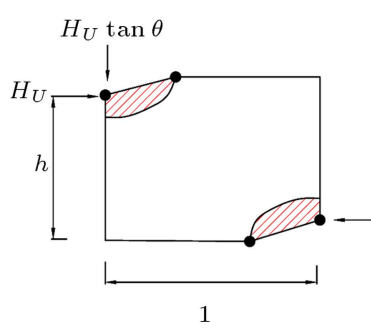

(b)

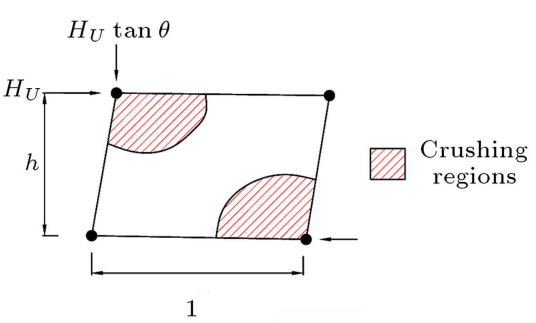

(c)

Figure 3. Different failure modes in Liauw and Kwan study [20] for ultimate strength estimation. 
in which the last term considers the frame contribution:

$$
\begin{aligned}
F_{u}= & \sigma_{c} \times t_{\text {inf }} \times\left(1-\alpha_{c}\right) \times \alpha_{c} H+\tau_{b} \times t_{\text {inf }} \times \alpha_{b} L \\
& +\frac{2 M_{P j}}{h_{\text {col }}}
\end{aligned}
$$

where $\sigma_{c}$ is a normal contact stress along the column, $\alpha_{c} H$ is the contact length along the column, $\tau_{b}$ is the shear stress along the beam, and $\alpha_{b} L$ is the contact length along the beam. $h_{\text {col }}$ is height of columns measured on center of the beams. $M_{P j}$ is plastic moment of the joint. The shear stress along the beam is determined as:

$$
\tau_{b}=\mu \times \sigma_{b},
$$

in which $\mu$ is coefficient of friction between the frame and infill, and $\sigma_{b}$ is normal contact stress on the beam.

The contact lengths of the infill to the columns and beams of the confining frames $\left(\alpha_{c} H\right.$ and $\alpha_{b} L$, respectively) are as follows:

$$
\begin{aligned}
& \alpha_{c} H=\sqrt{\frac{2 M_{p j}+2 \beta_{c} M_{p c}}{\sigma_{c} \times t_{\mathrm{inf}}}} \leq 0.4 h_{\mathrm{inf}}, \\
& \alpha_{b} L=\sqrt{\frac{2 M_{p j}+2 \beta_{b} M_{p b}}{\sigma_{b} \times t_{\mathrm{inf}}}} \leq 0.4 l_{\mathrm{inf}},
\end{aligned}
$$

in which $\beta_{c}$ and $\beta_{b}$ are reduction factors to account for non-ideal plasticity. The contact lengths are not constant and they vary throughout the loading history. Application of these relations is hard and that is why they are not applied in FEMAs [13-16] and also in this paper.

\section{Italian code [22]}

The Italian code [22] gives three failure mechanisms (Figure 4), which are as follows. Biondi et al. [23] compared results of this relation with experimental values.

a) Failure for sliding mechanism due to ultimate shear stress, $\tau_{u}$, at panel middle:

$$
\tau_{u}=f_{v} \times \sqrt{1+\frac{\left(0.8 \times h_{\mathrm{inf}}-0.2 \times l_{\mathrm{inf}}\right) \times F_{u}}{1.5 \times f_{v} \times l_{\mathrm{inf}}^{2} \times t_{\mathrm{inf}}}}
$$

Therefore, the ultimate strength of the infill panel for this failure mechanism is:

$$
F_{u}=\tau_{u} \times \frac{t_{\mathrm{inf}} \times l_{\mathrm{inf}}}{\varphi} .
$$

b) Diagonal failure due to ultimate tensile stress at the panel center:

$$
F_{u}=f_{v} \times \frac{t_{\mathrm{inf}} \times l_{\mathrm{inf}}}{0.6 \times \varphi} .
$$

c) This failure mechanism is for infilled concrete frames, in which local compressive crushing occurs at strut end due to stress concentration atreinforced concrete:

$$
\begin{aligned}
F_{u}= & 0.8 \times \frac{f_{k}}{\phi} \times \cos ^{2} \theta \\
& \times \sqrt[4]{\frac{E_{\mathrm{col}} \times I_{\mathrm{col}} \times h_{\mathrm{inf}} \times t_{\mathrm{inf}}^{3}}{E_{\mathrm{inf}}}}
\end{aligned}
$$

In the above-mentioned formulas, $\phi$ is the safety factor (which is equal to 1.0 in ultimate state criterion and 2.0 in admissible stress criterion), $f_{v}$ is the masonry shear strength without vertical load, given by Italian code, and $f_{k}$ is the masonry compressive strength. $I_{\text {col }}$ and $E_{\text {col }}$ are moment of inertia and modulus of elasticity of column, respectively.

\section{Hendry}

This relation was proposed by Hendry [24], based on calculating the contract area of the infill with the frame. Based on this research, the contact areas of infill with column and beam ( $a_{l}$ and $a_{h}$, respectively) are calculated by the following relations, respectively:

$$
\begin{gathered}
\alpha_{l}=\frac{\pi}{2} \sqrt[4]{\frac{4 E_{f} \times I_{\mathrm{col}} \times h_{\mathrm{inf}}}{E_{\mathrm{inf}} \times t_{\mathrm{inf}} \times \sin (2 \theta)}}, \\
\alpha_{h}=\frac{\pi}{2} \sqrt[4]{\frac{4 E_{f} \times I_{\mathrm{beam}} \times l_{\mathrm{inf}}}{E_{\mathrm{inf}} \times t_{\mathrm{inf}} \times \sin (2 \theta)}} .
\end{gathered}
$$

Based on these relations, width of the infill equivalent strut can be calculated as follows, and the ultimate strength of the infilled frame can be calculated by Eq. (1):

$$
a=\frac{1}{2} \sqrt{\alpha_{l}^{2}+\alpha_{h}^{2}}
$$

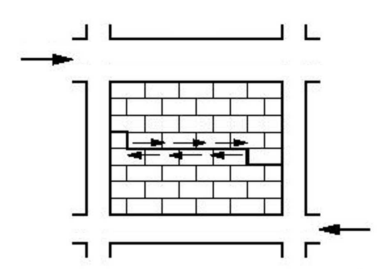

(a)

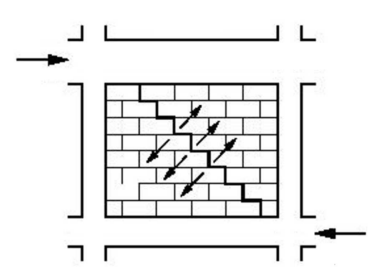

(b)

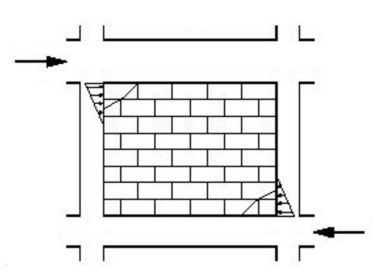

(c)

Figure 4. Assumed failure modes in Italian code. 


\section{Decanini \& Fantin [25]}

Decanini \& Fantin [25] proposed different relations for the equivalent strut width of intact and cracked infill panels as follows, each depending on $\lambda_{l}$, which was previously defined for Smith relation (Eq. (3)); $d$ is the infill diagonal length:

a) For intact infill panels:

$$
\begin{array}{ll}
\frac{a}{d}=0.085+\frac{0.748}{\lambda_{h}} & \lambda_{h}<7.85, \\
\frac{a}{d}=0.130+\frac{0.393}{\lambda_{h}} & \lambda_{h}>7.85 .
\end{array}
$$

b) For cracked infill panels:

$$
\begin{array}{ll}
\frac{a}{d}=0.010+\frac{0.707}{\lambda_{h}} & \lambda_{h}<7.85, \\
\frac{a}{d}=0.040+\frac{0.470}{\lambda_{h}} & \lambda_{h}>7.85 .
\end{array}
$$

Durrani \& Lou [26]

This relation was proposed by Durrani \& Lou [26] for width of the infill equivalent strut and was confirmed by Perera [27, which is as follows:

$$
a=\gamma \sqrt{h_{\mathrm{inf}}^{2}+l_{\mathrm{inf}}^{2}} \sin (2 \theta)
$$

where:

$$
\begin{aligned}
& \gamma=0.32 \sqrt{\sin (2 \theta)}\left(\frac{H \times E_{\mathrm{inf}} \times t_{\mathrm{inf}}}{m \times E_{\mathrm{col}} \times I_{\mathrm{col}} \times h_{\mathrm{inf}}}\right)^{-0.1}, \\
& m=6\left(1+\frac{6 H \times E_{\text {beam }} \times I_{\text {beam }}}{\pi E_{\mathrm{col}} \times I_{\mathrm{col}} \times L}\right),
\end{aligned}
$$

where $H$ and $L$ are the height and length of the frame (see Figure 1), respectively.

Some of the above-mentioned formulas are numerically compared by Samoila [28] for a typical infill in which the equivalent strut width was calculated by different formulas and compared. He showed analytically that the suggestion of Paulay \& Priestly to assume the infill equivalent strut width as $25 \%$ of the infill diagonal gives the best correlation with finite element results.

\section{Comparing the relations in previous studies of the literature}

Flanagan and Bennett $[29,30]$ compared some analytical methods for predicting corner crushing strength of nine specimens that were tested in their research. The specimens had clay tile infill panels. They showed that the average ratios of the experimental load to the analytical corner crushing load for formulas of Smith \&
Coull (Eq. (2)), Mainstone (Eq. (6)), Liauw \& Kwan (Eq. (9)), Saneinejad (Eq. (12)) were 0.38, 0.83, 1.02, and 0.52 , respectively, and their coefficients of variations were $0.35,0.38,0.36$, and 0.37 , respectively. Also, Mohammadi [31] studied accuracy of Mainstone formula for his ten specimens including masonry, concrete, and multi-layer infilled steel frames. He showed that the calculated ultimate strengths of most specimens are appropriately in accordance with the experiments. Nevertheless, the equivalent strut width calculated by Smith or Mainstone formula overestimates the stiffness of the specimens more than twice [31].

Some of the above-mentioned equations, such as Paulay and Priestly, as well as Eqs. (23) to (25) are proposed for the infill equivalent strut width to estimate the infilled frame stiffness; however, their robustness to estimate the ultimate strength, by Eq. (1), is checked here as follows.

\section{Experimental studies}

Results of experimental studies on infilled frames can be employed to verify the above-mentioned empirical equations and determine their accuracy. In each case, experimental ultimate strength of solid specimen is compared with the ones calculated by the formulas. In this regard, experimental programs, which have the following conditions, are chosen:

1. Solid infills are tested and properties of infill and frame materials are specified;

2. Ultimate strengths of the specimens are mentioned. For specimens with different ultimate strengths in each direction of the cyclic loading, the average value is assumed for the ultimate strength;

3. Testing models should be as similar as real structures (nonrealistic specimens in material, shape, and scaling are ignored).

Brief description of the selected experimental studies is presented as follows.

\section{Flanagan and Bennett [29]}

Flanagan and Bennett [29] investigated effects of frame stiffness, varying infill size, infill offset from frame centerline, and single and double wythe infill construction. For this, large scale cyclic static tests of structural clay tile infilled frames were carried out. Sequential and combined in-plane and out-of-plane loadings were also performed to determine the effects of orthogonal damage and degradation on strength and stiffness as well as the interaction of multi-directional loading. All specimens of this study, i.e. each consisted steel frame and clay tile infill, can be used here.

Flanagan and Bennett presented another paper [30] which was about three times the size of 
other specimens. The infill was $330 \mathrm{~mm}$ thick doublewythe structural clay tile masonry. This specimen, referred to as specimen $H$, is also applied in this study.

\section{Colangelo [32]}

Colangelo [32] tested five perforated-brick and mortar masonry infilled panels. All specimens had single-story, single-bay, and half-scale reinforced-concrete frames. The frames differed with respect to their aspect ratio and reinforcement, as deformed and round bars were alternatively used. All five specimens were used here.

\section{Bounopane and white [33]}

In this study [33], seismic evaluation of a two-story, two-bay reinforced concrete frame infilled with masonry was performed by pseudo-dynamic testing of a half-scale specimen. The specimen was subjected to four tests of increasing magnitude based on the Taft ground motion and shear of each story as well as its drift was measured. In the present study, the measured maximum base shear of the building (122 $\mathrm{kN}$ ) is assumed as the ultimate strength of the two-bay infilled frame of the first story and compared with the calculated values twice.

\section{Durrani and Haidar [34]}

In this research [34], four solid masonry infilled $\mathrm{R} / \mathrm{C}$ frames (named as specimens A, B, C, and D) were tested by cyclic loadings. Effects of infill aspect ratio on the stiffness, strength, and failure modes of the specimens were studied. It was shown that presence of infill in the frame raises the stiffness and strength highly. It was deduced that a reduction in aspect ratio results in lower strength and less effective energy dissipation while there is no significant effect on the stiffness.

All specimens can be used here, except for specimen "C", for which the test was stopped due to the base failure.

\section{Mehrabi et al. [35]}

In this paper [35], influence of masonry infill panels on the seismic performance of $\mathrm{R} / \mathrm{C}$ frames was investigated. For this, twelve $1 / 2$ - scale single-story single-bay frame specimens were tested to study the effects of the strength of infill panels with respect to that of the bounding frame, the panel aspect ratio, the distribution of vertical load between the column and the top beam with different relative stiffness of frame. It was shown that the presence of infills improves the performance of $\mathrm{R} / \mathrm{C}$ frames. However, specimens with strong frames and strong infills exhibited a better performance than those with weak infills and weak frames. All infill specimens of this study are applied here to evaluate accuracy of the proposed formula.

\section{Al-Chaar et al. [36]}

An experimental program was carried out by Al-Chaar et al. [36] to evaluate the behavior of five half-scale, single-story laboratory models with different numbers of bays. The results indicated that infilled RC frames exhibit significantly higher ultimate strength, residual strength, and initial stiffness than bare frames without compromising any ductility in the load-deflection response. In this study, the number of bays appeared to be influential with respect to the peak and residual capacity, the failure mode, and the shear stress distribution. All infill specimens of this study are used in the present paper.

\section{Colunga et al. [37]}

In this paper [37], results of the tests conducted for combined and confined masonry walls are reported. The confined masonry walls are usually made with fired clay bricks or concrete blocks confined with reinforced concrete tie-columns and bond-beams. Confined masonry is the dominant mode of construction for housing in Mexico. It is worth noting that the specimens of this paper had strong confining frame, and they can rather be considered as beams and columns; furthermore, they have significant hardening in their load-displacement behavior. Therefore, the specimens' walls are regarded as infills, considered here.

\section{Mohammadi [31]}

This paper [31] presented the results of an experimental and numerical investigation on many masonry, concrete, and multilayer infill specimens. Only one specimen of this study, named as MM, is applied in this paper. The specimen was a $2 / 3$-scale clay brick infilled steel frame.

\section{Calvi and Bolognini [38]}

Calvi and Bolognini [38] presented results of testing full-scale weak masonry panels (made of clay tile bricks) in single-story single-bay RC frames. Inplane and out-of-plane responses of the specimens were studied. Only one specimen of this paper is applied here, named as " 2 ".

\section{El-Dakhakhni et al. [39]}

This paper [39] included an experimental investigation on the effect of retrofitting unreinforced concrete masonry-infilled steel frame structures by Glass FiberReinforced Polymer (GFRP) laminates. For this, six full-scale single-story single-bay steel frames with different infill configurations were tested. Only one specimen of this study, unretrofitted solid wall infilled frame, named as SP-2, can be used here. 


\section{Kakaletsis and Karayannis [40]}

Seven 1/3-scale, single-story, single-bay $\mathrm{R} / \mathrm{C}$ frame specimens were tested in this paper [40] under cyclic horizontal loading up to a drift level of $40 \%$. Two types of masonry infill, i.e. weak and strong (clay brick and vitrified ceramic brick, respectively), were studied. The investigated parameters were the opening shape and the infill compressive strength. Two solid infill specimens of the paper ( $S$ and IS specimens) can be used here.

\section{Tasnimi and Mohebkhah [41]}

This research [41] deals with an experimental program to investigate the in-plane seismic behavior of steel frames with clay brick masonry infills having openings. Six large-scale, single-story, single-bay frame specimens were tested under in-plane cyclic loading. All specimens were $2400 \mathrm{~mm}$ long by $1870 \mathrm{~mm}$ high. Infill panels consisted of $219 \times 110 \times 66 \mathrm{~mm}$ solid clay bricks (with no voids). The infill panel specimens included masonry infills having central openings of various dimensions. They showed that the ductility of perforated frames depends on the failure mode of infill piers. One specimen of this study (a solid specimen named as SW) is applied here.

\section{Kaltace et al. [42]}

In the paper of Kaltac et al. [42], experimental failure loads and failure types of 30 partially and fully infilled steel frame systems were determined. The specimens were tested under reversed cyclic loading. Influence of infill material and size, number of story, and bay were all investigated. An analytical study was also carried out to determine the failure load and failure modes of the specimens, using the equivalent strut tie method.

Seven single-story single-bay solid infill specimens of the paper are applied here.

\section{Verification of the proposed formulas by experimental test results}

The proposed analytical methods and experimental programs have been explained in previous sections. In this section, the accuracy of the proposed analytical methods for the ultimate strength of the specimens is studied by implementing the results of the experimental tests, shown in Table 1.

As shown in Table 1, all formulas are applied to all specimens, except for Liauw \& Kwan relation that could not be used for the specimens of Kaltac et al. (seven specimens with steel frames) due to the lack of the required data of this formula. The average and standard deviations (STD) of the formulas' error are presented in Table 2. Regarding the average error, for the whole specimens considered in this paper, especially for those with concrete frames, Mainstone equation presents the best prediction (regarding the average value). Despite its standard deviation (41.4\%) which is greater than that of Liauw \& Kwan and also Italian code relations, this relation normally underestimates the ultimate strength. For specimens with steel frame, if both relations (Liauw \& Kwan and Mainstone relations) are applied to the same specimens (ignoring specimens of Kaltac et. al. for the both), Liauw \& Kwan give $-14 \%$ and $23.5 \%$ for the average error and standard deviation, respectively, while Mainstone gives these parameters as $-6.5 \%$ and $30.6 \%$, respectively. This shows that Mainstone relation is more accurate.

In summary, Mainstone formula gives more accurate result of infill panel ultimate strength for both concrete and steel frames, regarding the average error of the obtained results.

\section{Improved mainstone formula}

Based on the experimental results, summarized in Table 2, it can be concluded that Mainstone formula can estimate the maximum strength of infilled frames more accurately than the other proposed relations. However, its average error is $-13.1 \%$ for the considered 51 specimens. The formula can be improved as follows:

$$
a=0.201 \times\left(\lambda_{1} \times h_{\mathrm{col}}\right)^{-0.4} r_{\mathrm{inf}}
$$

This relation is similar to Eq. (6), in which the coefficient is changed from 0.175 to 0.201 . Recalculating the ultimate strengths of the whole specimens in Table 1 gives $-0.12 \%$ and 47.5 as the average and standard deviations of the error, respectively. Comparing the results of the improved formula with the original one shows that the average error is decreased from $-13.1 \%$ to $-0.12 \%$; however, the standard deviation of the error is raised a little from $41.35 \%$ to $47.5 \%$.

\section{Conclusion}

Some empirical formulas, proposed by previous researchers to estimate the ultimate strength of infilled frames, which are based on the results of some numerical or experimental test results, are mentioned in this paper. The accuracy of the formulas is investigated in this paper through the analysis of the results derived from existing experimental data. All of these studies included solid infills.

Nine empirical formulas are studied here. The results show that the equation proposed by Mainstone estimates the ultimate strength of the specimens more accurately than the others, with an average error of less than $13.1 \%$. The formula can be improved if the equivalent width proposed by this formula is raised $115 \%$. Therefore, the improved version of the 
Table 1. Comparing the calculated and experimental ultimate strengths.

\begin{tabular}{|c|c|c|c|c|c|c|c|c|c|c|c|c|c|c|c|c|c|c|c|c|c|c|}
\hline \multirow{3}{*}{$\begin{array}{l} \\
\Xi \\
\pm \\
\pm \\
\pm\end{array}$} & \multirow{3}{*}{ 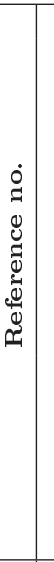 } & \multirow{3}{*}{ 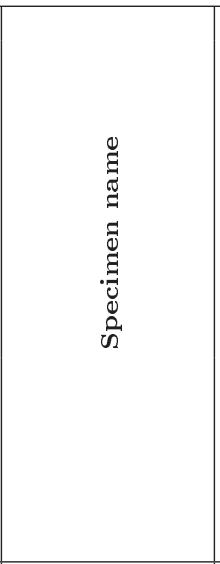 } & \multirow{3}{*}{ 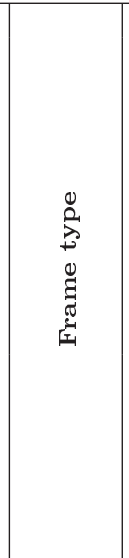 } & \multirow{3}{*}{ 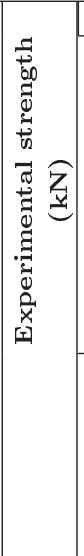 } & \multicolumn{18}{|c|}{ Numerical strength } \\
\hline & & & & & \multicolumn{2}{|c|}{ 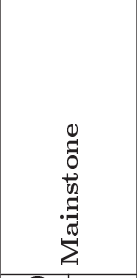 } & \multicolumn{2}{|c|}{ 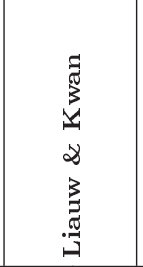 } & \multicolumn{2}{|c|}{ 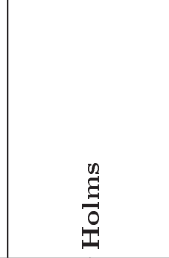 } & \multicolumn{2}{|c|}{ 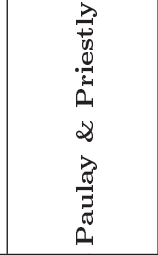 } & \multicolumn{2}{|c|}{ 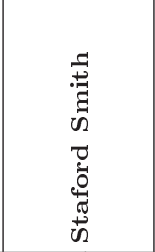 } & 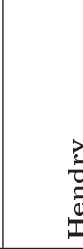 & & & 苂 & & 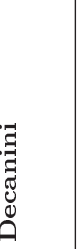 & & 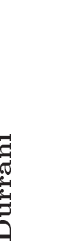 \\
\hline & & & & & 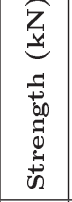 & 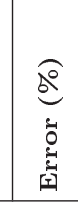 & 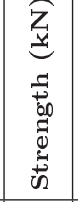 & 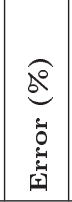 & 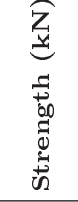 & 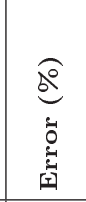 & 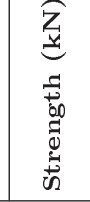 & 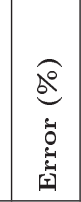 & 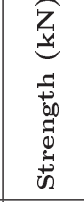 & 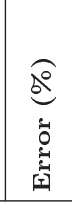 & 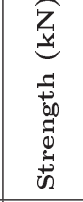 & 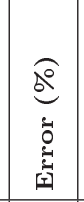 & 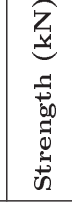 & 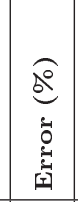 & 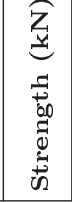 & 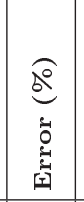 & 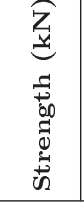 & 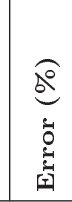 \\
\hline 1 & & me 1 & teel & 143.5 & 94.5 & -34.1 & 80.5 & $\mid-43.9$ & 450.0 & 213.6 & 337.5 & 135.2 & 236.2 & 64.6 & 301.4 & 110.1 & 46.0 & -67.9 & 118.2 & -17.6 & 312.1 & 117.5 \\
\hline 2 & & Frame 2 & Steel & 174.5 & 115.9 & -33.6 & 127.9 & -26.7 & 450.0 & 157.9 & 337.5 & 93.4 & 393.4 & 125.5 & 322.7 & 84.9 & 76.7 & -56.0 & 174.5 & 0.0 & 312.9 & 79.3 \\
\hline 3 & & Frame 3 & Steel & 176.0 & 130.1 & -26.1 & 163.7 & -7.0 & 450.0 & 155.7 & 337.5 & 91.8 & 524.5 & 198.0 & 346.9 & 97.1 & 102.2 & $2-41.9$ & 228.1 & 29.6 & 314.8 & 78.9 \\
\hline 4 & & ne 4 & Steel & 192.0 & 171.0 & -10.9 & 159.6 & -16.9 & 742.5 & 286.7 & 556.9 & 190.0 & 506.7 & 163.9 & 666.9 & 247.4 & 103.6 & -46.0 & 223.1 & 16.2 & 559.4 & 191.4 \\
\hline & 29] & 5 & eel & 182.0 & 190.7 & 4.8 & 201.6 & 10.8 & 742.5 & 308.0 & 556.9 & 206.0 & 665.0 & 265.4 & 599.9 & 229.6 & 135.8 & -25.4 & 286.0 & 57.2 & 26.7 & 189.4 \\
\hline 6 & & Frame 7 & Steel & 134.5 & 115.9 & -13.8 & 127.9 & -4.9 & 450.0 & 234.6 & 337.5 & 150.9 & 393.4 & 192.5 & 322.7 & 140.0 & 76.7 & -43.0 & 174.5 & 29.7 & 312.9 & 132.7 \\
\hline 7 & & Frame 9 & Steel & 215.0 & 163.6 & -23.9 & 144.4 & -32.8 & 503.2 & 134.0 & 377.4 & 75.5 & 738.9 & 243.7 & 407.2 & 89.4 & 150.5 & $5-30.0$ & 337.4 & 56.9 & 349.4 & 62.5 \\
\hline 8 & & Frame 17 & Steel & 211.0 & 181.1 & -14.2 & 143.1 & $\mid-32.2$ & 694.0 & 228.9 & 520.5 & 146.7 & 473.2 & 124.3 & 424.1 & 101.0 & 104.1 & -50.7 & 277.1 & 31.3 & 382.1 & 81.1 \\
\hline 9 & & $\mathrm{~F}$ & Steel & 193.0 & 148.1 & -23.3 & 137.8 & -28.6 & 572.0 & 196.4 & 429.0 & 122.3 & 438.1 & 127.0 & 377.3 & 95.5 & 92.7 & -51.9 & 224.3 & 16.2 & 360.6 & 86.9 \\
\hline 10[ & [30] & $\mathrm{H}$ & Steel & 200.0 & 339.5 & \begin{tabular}{|l|l|}
69.7 \\
\end{tabular} & 259.7 & 29.9 & 1850.7 & 825.3 & 1388.0 & 594.0 & 595.0 & 197.5 & 461.9 & 130.9 & 116.0 & -42.0 & 410.4 & 105.2 & 861.1 & 330.5 \\
\hline 11 & & & ncrete & 155.0 & \begin{tabular}{|l|}
68.1 \\
\end{tabular} & $\mid-56.0$ & 53.9 & -65.2 & 203.1 & 31.0 & 152.3 & -1.7 & 293.9 & 89.6 & 171.9 & 10.9 & 60.3 & $\mid-61.1$ & 146.7 & -5.4 & 0.1 & -9.6 \\
\hline 12 & & & te & 159.0 & 68.6 & -56.9 & 53.2 & -66.5 & 203.1 & 27.7 & 2.3 & -4.2 & 8.9 & 88.0 & 4.8 & 10.0 & 61.4 & -61.4 & 149.0 & -6.3 & 41.0 & -11.3 \\
\hline 13[ & & V11 & Concrete & 190.0 & 93.2 & -50.9 & 57.6 & -69.7 & 274.8 & 44.6 & 206.1 & 8.5 & 331.6 & 74.5 & 202.6 & 6.6 & 72.4 & -61.9 & 204.0 & 7.4 & 155.4 & -18.2 \\
\hline 14 & & V21 & Concrete & 175.0 & 92.4 & -47.2 & 56.8 & -67.6 & 274.8 & 57.0 & 206.1 & 17.8 & 323.8 & 85.1 & 197.8 & 13.0 & 70.7 & -59.6 & 199.4 & 14.0 & 153.9 & -12.0 \\
\hline 15 & & V22 & Concrete & 221.0 & 92.8 & -58.0 & 56.8 & -74.3 & 274.8 & 24.3 & 206.1 & -6.8 & 328.1 & 48.4 & 200.4 & -9.3 & 71.6 & -67.6 & 201.9 & -8.6 & 154.7 & -30.0 \\
\hline 16[ & [33] & afill spe & Concrete & 122.0 & 157.8 & 29.3 & 101.4 & -16.9 & 580.0 & 375.4 & 435.0 & 256.6 & \begin{tabular}{|l|l|}
482.0 \\
\end{tabular} & 295.1 & 310.4 & 154.4 & 99.3 & -18.6 & 255.1 & 109.1 & 336.5 & 175.8 \\
\hline 17 & & A & e & 221.0 & 111.2 & -49.7 & 162.3 & -26.5 & 638.4 & 38.9 & 478.8 & 116.7 & 7.8 & -1.5 & 2.0 & $\mid-49.3$ & 39.7 & -82.0 & 133.7 & -39.5 & 235.6 & 6.6 \\
\hline 18[ & & B & & 272.1 & 128.7 & -52.7 & 164.2 & -39.7 & 682.0 & 0.7 & 1.5 & 88.0 & 291.1 & .0 & 18.8 & -45.3 & 51.6 & -81.0 & 156.3 & -42.5 & 272.1 & 0.0 \\
\hline 19 & & $\mathrm{D}$ & Concrete & 245.6 & 127.1 & -48.2 & 135.8 & -44.7 & 688.3 & 80.2 & 516.2 & 110.2 & 309.6 & 26.0 & 145.2 & -40.9 & 45.9 & -81.3 & 153.9 & -37.4 & 239.9 & -2.3 \\
\hline 20 & & 2 & Concrete & 146.9 & 199.3 & 35.7 & 135.9 & -7.5 & 624.2 & 325.0 & 468.1 & 218.8 & 724.5 & 393.3 & 424.8 & 189.3 & 153.1 & 4.3 & 400.7 & 172.9 & 379.3 & 158.3 \\
\hline 21 & & 3 & ncrete & 277.7 & 279.1 & 0.5 & 184.0 & -33.7 & 976.4 & 51.6 & 732.3 & 163.7 & 859.5 & 209.5 & 504.1 & 81.5 & 181.7 & $7-34.6$ & 482.5 & 73.8 & 531.2 & 91.3 \\
\hline 22 & & 4 & te & .0 & 206.1 & 30.5 & 143.5 & -9.2 & 686.5 & 4.6 & 4.9 & 225.9 & 682.7 & 332.1 & 400.3 & 153.4 & 144.3 & $3-8.7$ & 380.6 & 140.9 & 392.1 & 148.2 \\
\hline 23 & & 5 & e & 249.6 & 252.9 & 1.3 & 170.1 & $\mid-31.8$ & 896.1 & 99.0 & 2.1 & 169.3 & 763.3 & 205.8 & 447.6 & 79.3 & 161.3 & -35.4 & 429.4 & 72.0 & 481.1 & 92.8 \\
\hline 24 & & 6 & te & 197.8 & 212.4 & $\begin{array}{l}4.4 \\
\end{array}$ & 157.2 & -20.5 & 655.4 & 31.3 & 1.5 & 148.5 & 789.3 & 299.1 & 428.5 & 116.6 & 166.8 & -15.7 & 435.9 & 120.4 & 390.3 & 97.3 \\
\hline 25[ & & 7 & Concrete & 467.3 & 261.8 & -44.0 & 189.7 . & -59.4 & 878.3 & 88.0 & 58.7 & 41.0 & 858.5 & 83.7 & 466.0 & -0.3 & 181.4 & $4-61.2$ & 479.0 & 2.5 & 481.2 & 3.0 \\
\hline 26 & & 8 & Concrete & 190.0 & 182.8 & \begin{tabular}{|l|l|} 
& -3.8 \\
\end{tabular} & 133.7 . & -29.6 & 615.2 & 223.8 & 61.4 & 142.9 & 596.1 & 213.7 & 349.6 & 84.0 & 126.0 & -33.7 & 332.8 & 75.1 & 347.8 & 83.0 \\
\hline 27 & & 9 & Concrete & 292.8 & 260.1 & -11.2 & 175.2 & -40.2 & 918.4 & 213.7 & 688.8 & 135.2 & 789.4 & 169.6 & 462.9 & 58.1 & 166.8 & -43.0 & 443.8 & 51.6 & 494.9 & 69.0 \\
\hline 28 & & 10 & & $.9:$ & 301.9 & 74.6 & 149.7 . & -13.4 & 958.7 & 4.5 & 9.0 & 315.9 & 835.5 & 383.3 & 515.0 & 197.9 & 183.8 & \begin{tabular}{|l|l|}
8 & 6.3 \\
\end{tabular} & 595.2 & 244.3 & 429.4 & 148.4 \\
\hline 29 & & 11 & e & 284.4 & 294.6 & 3.6 & 156.7 & -44.9 & 1033.4 & 263.4 & 5.1 & 172.6 & 702.3 & 147.0 & 432.9 & 52.3 & 154.5 & $5-45.7$ & 507.1 & 78.4 & 419.1 & 47.4 \\
\hline 30 & & 12 & Concrete & $359.1:$ & 362.9 & 1.1 & 176.0 & -51.0 & 1226.4 & 241.5 & 19.8 & 156.1 & 915.2 & 154.9 & 564.2 & 57.1 & 201.4 & $4-43.9$ & 657.3 & 83.0 & 516.3 & 43.8 \\
\hline \begin{tabular}{|l|}
31 \\
\end{tabular} & & 2 & Concrete & 84.1 & 176.3 & 109.6 & 161.0 & 91.5 & 1213.0 & 1342.4 & 909.8 & 981.8 & 214.1 & 154.6 & 111.7 & 32.8 & 43.4 & -48.4 & 214.5 & 155.1 & 347.5 & 313.2 \\
\hline 32 & & 3 & Concrete & 89.0 & 158.9 & 78.5 & 151.7 & 70.4 & 1080.8 & 1114.4 & 810.6 & 810.8 & $\mid 196.4$ & 120.7 & 102.4 & 15.1 & 39.8 & -55.3 & 192.9 & 116.8 & 313.2 & 251.9 \\
\hline $33^{L^{2}}$ & & 4 & Concrete & 158.8 & 176.3 & 11.0 & 161.0 & 1.4 & 1213.0 & 663.9 & 909.8 & 472.9 & 214.1 & 34.9 & 111.7 & -29.7 & 43.4 & -72.7 & 214.5 & 35.1 & 347.5 & 118.8 \\
\hline 34 & & 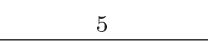 & rete & 123.0 & 158.9 & 29.2 & 151.7 & 23.3 & 1080.8 & 778.7 & 810.6 & 559.0 & 196.4 & 59.7 & 102.4 & -16.7 & 39.8 & -67.6 & 192.9 & 56.9 & 313.2 & 154.7 \\
\hline 35 & & & & 78.5 & 68.1 & $\mid-13.2$ & 53.5 & -31.8 & 225.8 & & 169.3 & 115.9 & 293.1 & 273.7 & 177.1 & 125.7 & 52.4 & $\mid-33.3$ & 126.5 & 61.3 & 158.5 & 102.0 \\
\hline 36 & & & & & 57.4 & -25.4 & 46.5 & -39.6 & 189.4 & & 2.0 & 84.4 & 249.0 & 223.4 & 150.4 & 95.4 & 44.5 & -42.2 & 107.4 & 39.5 & 33.6 & 73.5 \\
\hline $37^{2}$ & & $\mathrm{C}-3$ & Concrete & 67.7 & 49.2 & -27.3 & 42.3 & -37.4 & 167.5 & 17.6 & 125.6 & 85.7 & 203.6 & 201.0 & 123.0 & 81.8 & 36.4 & -46.2 & 88.2 & 30.4 & 114.5 & 69.3 \\
\hline 38 & & MCC-4 & Concrete & 58.4 & 49.7 & -14.9 & 42.3 & -27.5 & 167.5 & 187.1 & 125.6 & 115.3 & 208.6 & 257.4 & 126.0 & 115.9 & 37.3 & -36.2 & 90.2 & 54.6 & 115.6 & 98.2 \\
\hline 39[ & [31] & MM & Steel & 147.2 & 130.6 & -11.2 & 105.2 & -28.5 & 467.1 & 217.4 & 350.4 & 138.1 & 382.1 & 159.7 & 202.3 & 37.5 & 79.2 & -46.2 & 219.2 & 48.9 & 244.8 & 66.3 \\
\hline 40[ & [38] & 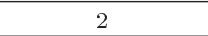 & Concrete & 248.0 & 55.8 & -77.5 & 51.6 & $\mid-79.2$ & 207.9 & -16.2 & 155.9 & -37.1 & 148.4 & -40.2 & \begin{tabular}{|l|}
83.1 \\
\end{tabular} & -66.5 & 31.3 & -87.4 & 88.8 & $\mid-64.2$ & 101.9 & -58.9 \\
\hline 41[ & [39] & SP-2 & Steel & 428.0 & 618.8 & 44.6 & 539.5 & 26.0 & 2286.0 & 434.1 & 1714.5 & 300.6 & 1940.6 & 353.4 & 1008.6 & 135.7 & 383.1 & $1-10.5$ & 994.2 & 132.3 & 1258.2 & 2194.0 \\
\hline 42 & & $\mathrm{~S}$ & oncrete & 81.5 & 21.7 & -73.4 & 23.4 & -71.2 & 63.1 & -22.5 & 47.3 & $\mid-41.9$ & \begin{tabular}{|l|}
90.8 \\
\end{tabular} & 11.4 & 52.7 & $|-35.3|$ & 19.4 & $\mid-76.2$ & 48.2 & $\mid-40.8$ & 40.5 & -50.2 \\
\hline $43^{\mathrm{L}^{-}}$ & & 15 & Concrete & 72.9 & 95.1 & 30.4 & 57.8 & -20.7 & 315.7 & 333.0 & 236.8 & 224.8 & 327.0 & 348.4 & 189.7 & 160.2 & 70.0 & -4.0 & 176.3 & 141.8 & 177.9 & 143.9 \\
\hline 44[ & [41] & & & 201.5 & 176.1 & -12.6 & 146.1 . & -27.5 & 651.2 & 223.2 & 488.4 & 142.4 & 526.8 & 161.4 & 275.3 & 36.6 & 106.0 & -47.4 & 282.6 & 40.3 & 349.3 & 73.3 \\
\hline 45 & & 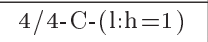 & & 41.4 & 14.2 & -65.7 & - & - & 45.4 & & 34.0 & -17.9 & 60.6 & 46.4 & 30.6 & $\mid-26.1$ & 11.2 & -73.0 & 27.9 & -32.6 & 0.1 & -27.3 \\
\hline 46 & & 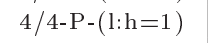 & & 56.9 & 24.3 & -57.4 & 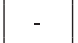 & - & 82.1 & 44.2 & 61.5 & 0.1 & 94.6 & 66.2 & 47.8 & -16.1 & 17.4 & -69.4 & 43.9 & -22.9 & 1.4 & -9.7 \\
\hline $47 \mid$ & & $4 / 4-\mathrm{AAC}-(1: \mathrm{h}=1)$ & Steel & 42.5 & 15.2 & -64.3 & & - & 48.7 & 14.6 & 36.5 & -14.0 & 64.0 & 50.5 & 32.3 & -24.0 & 11.8 & -72.3 & 29.5 & $-30.7 \mid$ & 32.1 & -24.4 \\
\hline 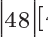 & & $4 / 4-\mathrm{C}-(1: \mathrm{h}=2)$ & eel & 45.4 & 28.9 & -36.2 & & 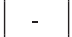 & 90.2 & 98.6 & 67.6 & 48.9 & 80.6 & 77.6 & 4.7 & -1.4 & 17.6 & $|-61.3|$ & 58.6 & 29.2 & 0.5 & -10.8 \\
\hline$\left.49\right|^{2}$ & & $4 / 4-\mathrm{P}-(\mathrm{l}: \mathrm{h}$ & teel & 65.2 & 49.4 & -24.3 & - & - & 163.1 & 150.1 & 122.3 & 87.5 & 125.8 & 92.8 & 9.8 & 7.0 & 27.4 & -58.0 & 92.2 & 41.3 & 9.1 & 5.9 \\
\hline 50 & & $4 / 4-\mathrm{C}-(\mathrm{l}: \mathrm{h}=1 / 2$ & Steel & 22.5 & 11.9 & -47.0 & 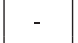 & - & 45.4 & 102.0 & 34.0 & 51.5 & 48.5 & 116.0 & 22.6 & 0.6 & 5.4 & -75.9 & 18.4 & -18.1 & 9.1 & 15.0 \\
\hline 51 & & $4 / 4-\mathrm{P}-(1: \mathrm{h}=1 / 2)$ & Steel & 26.5 & 20.3 & -23.4 & - & - & 82.1 & 209.5 & 61.5 & 132.2 & \begin{tabular}{|l|}
75.7 \\
\end{tabular} & 185.5 & 35.2 & 33.0 & 8.4 & -68.1 & 29.0 & 9.5 & 32.6 & 22.8 \\
\hline
\end{tabular}


Table 2. Summary of the results, including average error and standard deviations of the formulas.

\begin{tabular}{|c|c|c|c|c|c|c|c|c|c|c|}
\hline \multirow{2}{*}{$\begin{array}{c}\text { Frame } \\
\text { type }\end{array}$} & & \multicolumn{9}{|c|}{ Calculated strength $(\mathrm{kN})$} \\
\hline & & Mainstone & $\begin{array}{c}\text { Liauw \& } \\
\text { Kwan }\end{array}$ & Holms & $\begin{array}{c}\text { Paulay \& } \\
\text { Priestly }\end{array}$ & $\begin{array}{l}\text { Staford } \\
\text { Smith }\end{array}$ & Hendry & $\begin{array}{c}\text { Italian } \\
\text { code }\end{array}$ & Decanini & Dur \\
\hline \multirow{3}{*}{ Steel frame } & Average err. $(\%)$ & $-20.1-6.5$ & -14.0 & 278.1 & 183.6 & 182.8 & 118.1 & -43.0 & 42.0 & 129.5 \\
\hline & STD err. $(\%)$ & $32.5 \quad 30.6$ & 23.5 & 176.3 & 132.2 & 78.8 & 78.4 & 17.3 & 42.6 & 92.2 \\
\hline & No. of specimens & 20 & 13 & 20 & 20 & 20 & 20 & 20 & 20 & 20 \\
\hline \multirow{3}{*}{ Concrete frame } & Average err. $(\%)$ & -8.6 & -30.1 & 284.8 & 188.6 & 159.7 & 51.5 & -46.9 & 54.6 & 74.1 \\
\hline & STD err. (\%) & 46.1 & 38.3 & 309.9 & 232.4 & 121.3 & 74.9 & 25.8 & 72.5 & 87.6 \\
\hline & No. of specimens & 31 & 31 & 31 & 31 & 31 & 31 & 31 & 31 & 31 \\
\hline \multirow{3}{*}{ All speci. } & Average err. $(\%)$ & -13.1 & -25.4 & 282.8 & 187.1 & 166.5 & 71.2 & -45.8 & 50.9 & 90.5 \\
\hline & STD err. (\%) & 41.4 & 35.1 & 265.9 & 199.4 & 105.8 & 76.4 & 22.8 & 63.6 & 88.5 \\
\hline & No. of specimens & 51 & 43 & 51 & 51 & 51 & 51 & 51 & 51 & 51 \\
\hline
\end{tabular}

Mainstone formula is proposed, and it is shown that the average error of this formula for the ultimate strength estimation of 51 specimens is ignorable.

\section{References}

1. Moghaddam, H.A. and Dowling, P.J. "The state of the art in infilled frames", ESEE Research Report No. 872, Imperial College of Science and Technology. Civil Eng. Department, London, UK. (1987).

2. ASCE/SEI-7-05, Minimum Design Loads for Buildings and Other Structures, ASCE Standard (2006).

3. Iranian Standards No. 2800, Iranian Code of Practice for Seismic Resistant Design of Buildings, 4th edition, Road, Housing and Urban Development Research Center (2015).

4. ASCE 41-10, Seismic Rehabilitation of Existing Buildings, American Society of Civil Engineering (2010).

5. Instruction for Seismic Rehabilitation of Existing Buildings, No. 360 (First Revision), Office of Deputy for Strategic Supervision, Department of Technical Affairs (2014).

6. Instructions for Seismic Evolution and Rehabilitation of Existing School Buildings with Infill Panels, No. 398, Office of Deputy for Strategic Supervision, Department of Technical Affairs (2015).

7. Holmes, M. "Steel frames with brickwork and concrete infilling", Proceedings of the Institution of Civil Engineers, 19(4), pp. 473-478 (1961).

8. Paulay, T. and Priestley, M.J.N., Seismic Design of Reinforced Concrete and Masonry Buildings, John Wiley \& Sons, New York (1992).

9. Smith, B.S. and Coull, A., Tall Building Structures Analysis and Design, John Wiley and Sons Inc., New York etc. (1991).

10. Smith, B.S. "Behavior of square infilled frames", Journal of the Structural Division, 92(1), pp. 381-404 (1966).
11. Mainstone, R.J. "On the stiffness and strength of infilled frames", Proc., Supplement (IV), Trans. of Instn. of Civ. Engnrs., London, England (1971).

12. Mainstone, R.J., Supplementary Note on the Stiffness and Strength of Infilled Frames, Building Research Station, Garston, Watford, U.K (1974).

13. FEMA 273, NEHRP Guidelines for the Seismic Rehabilitation of Builsings, Federal Emergency Management Agency, (1997).

14. FEMA 306, Evaluation of Earthquake Damaged Concrete and Masonry Wall Buildings-Basic Procedures Manual, Applied Technology Council, ATC-43 Project, Washington D.C.: Federal Emergency Management Agency (1999).

15. FEMA 307, Evaluation of Earthquake Damaged Concrete and Masonry Wall Buildings, Applied Technology Council (1998).

16. FEMA 356, Prestandard for the Seismic Rehabilitation of Buildings, Federal Emergency Management Agency, Washington, DC (2000).

17. Zarnic, R. and Gostic, S. "Masonry infilled frames as an effective structural sub-assemblage", Seismic Design Methodologies for the Next Generation of Codes, Balkema: Rotterdam, pp. 335-346 (1997).

18. Dolsek, M. and Fajfar, P. "Mathematical modelling of an infilled RC frame structure based on the results of pseudo-dynamic tests", Earthquake Engineering \& structural Dynamics, 31(6), pp. 1215-1230 (2002).

19. Wood, R.H. "Plasticity, composite action and collapse design of unreinforced shear wall panels in frames", ICE Proceedings, 65(2), pp. 381-411, Thomas Telford (1978).

20. Liauw, T.C. and Kwan, K.H. "Plastic theory of nonintegral infilled frames", Proc. Inst. Civ. Eng., 75, pp. 379-396 (1983).

21. Saneinejad, A. and Hobbs, B. "Inelastic design of infilled frames ", Journal of Structural Engineering, 121(4), pp. 634-650 (1995). 
22. Decreto Min. LL.PP. 20.11.1987 "Technical standards for the design, construction and testing of masonry buildings and their strengthening" [ Norme tecniche per la progettazione, esecuzione e collaudo degli edifici in muratura e per il loro consolidamento], Roma: Gazzetta Ufficiale, 285, (in Italian) (1987).

23. Biondi, S., Candigliota, E. and Nuti, C. "Tests on different infilled specimens: a critical review of Code ultimate state criteria", In Proc. 12th European Conference on Earthquake Engineering, pp. 9-13 (2002).

24. Hendry, A., Structural Brickwork, Macmillan, London (1981).

25. Decanini, L.D. and Fantin, G.E. "Simplified models of masonry; characteristics of stiffness and lateral resistance in limit state", Jornadas Argentinas de Ingenieria Estructural, pp. 817-836 (1986).

26. Durrani, A.J. and Luo, Y.H. "Seismic retrofit of flat-slab buildings with masonry infills", In Technical Report, pp. 1-8. National Center for Earthquake Engineering Research, (1994).

27. Perera, R. "Performance evaluation of masonry-infilled RC frames under cyclic loading based on damage mechanics", Engineering Structures, 27(8), pp. 12781288 (2005).

28. Samoila, D.M. "Analytical modeling of masonry infills", Acta Technica Napocensis, Civil Engineering \& Architecture, 55(2), pp. 127-136 (2012).

29. Flanagan, R.D. and Bennett, R.M. "Bidirectional behavior of structural clay tile infilled frames", Journal of Structural Engineering, 125(3), pp. 236-244 (1999).

30. Flanagan, R.D. and Bennett, R.M. "In-plane behavior of structural clay tile infilled frames", Journal of Structural Engineering, 125(6), pp. 590-599 (1999).

31. Mohammadi, G.H. "Stiffness and damping of infilled steel frames", Proceedings of the Institution of Civil Engineers-Structures and Buildings, 160(2), pp. 105118 (2007).

32. Colangelo, F. "Pseudo-dynamic seismic response of infilled RC designed for gravity loading frames", Vancouver, Canada: 13th World Conference on Earthquake Engineering (2004).

33. Buonopane, S.G. and White, R.N. "Pseudo dynamic testing of masonry infilled reinforced concrete frame", Journal of Structural Engineering, 125(6), pp. 578-589 (1999).

34. Durrani, A.J. and Haider, S. "Seismic response of R/C frames with unreinforced masonry infills", Proceedings of the 11th World Conference on Earthquake Engineering (1996).
35. Mehrabi, A.B., Shing, P., Schuller, M.P. and Noland, J.L. "Experimental evaluation of masonry-infilled RC frames", Journal of Structural Engineering, 122(3), pp. 228-237 (1996).

36. Al-Chaar, G., Issa, M. and Sweeney, S. "Behavior of masonry-infilled nonductile reinforced concrete frames", Journal of Structural Engineering, 128(8), pp. 1055-1063 (2002).

37. Tena-Colunga, A., Juárez-Angeles, A. and SalinasVallejo, V.H. "Cyclic behavior of combined and confined masonry walls", Engineering Structures, 31(1), pp. 240-259 (2009).

38. Calvi, G.M. and Bolognini, D. "Seismic response of reinforced concrete frames infilled with weakly reinforced masonry panels", Journal of Earthquake Engineering, 5(02), pp. 153-185 (2001).

39. El-Dakhakhni, W.W., Hamid, A.A. and Elgaaly, M. "Seismic retrofit of concrete-masonry-infilled steel frames with glass fiber-reinforced polymer laminates", Journal of Structural Engineering, 130(9), pp. 13431352 (2004).

40. Kakaletsis, D.J. and Karayannis, C.G. "Influence of masonry strength and openings on infilled R/C frames under cycling loading", Journal of Earthquake Engineering, 12(2), pp. 197-221 (2008).

41. Tasnimi, A.A. and Mohebkhah, A. "Investigation on the behavior of brick-infilled steel frames with openings, experimental and analytical approaches", Engineering Structures, 33(3), pp. 968-980 (2011).

42. Kaltakcı, M.Y., Köken, A. and Korkmaz, H.H. "Analytical solutions using the equivalent strut tie method of infilled steel frames and experimental verification", Canadian Journal of Civil Engineering, 33(5), pp. 632638 (2006).

\section{Biography}

Majid Mohammadi obtained his BSc, MSc, and PhD degrees from Sharif University of Technology. He was graduated in 2007. He is now an Assistant Professor of the Structural Research Center in International Institute of Earthquake Engineering and Seismology (IIEES). Infilled frame is one of the main subjects of his studies, and he has recently prepared Code 398 to apply infill panels for rehabilitation of some schools, published by Iranian Organization of Managing and planning. 